\title{
The Hydropower Resources of Georgia and Use of their Economical and Ecological Challenges
}

\author{
Demur Chomakhidze* and David Tsiskaridze \\ Georgian Technical University, Georgia \\ *Corresponding author: Demur Chomakhidze, Professor of Georgian Technical University, PhD in Economic Science, Georgia
}

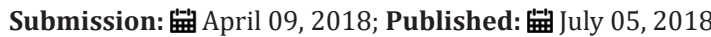

\begin{abstract}
The paper explains the renewable energy resources of Georgia quantitatively and qualitatively in country and regional contexts. It is mentioned that Georgia is rich in this regard and in some degree it fills the lack of fuel resources (oil, natural gas) in the country. It comes 3.27MMkWh energy of river surface runoffs on each square kilometer of the territory.In this regard, it is a better situation with the use of hydro power resources. However, according to 2016 year data, Georgian HPPs worked out only $11.4 \%$ of their technical capacity and $23.6 \%$ of their economic potential.There are some measures for improving the use of hydropower resources, in terms of technical and economical and ecological context as well.
\end{abstract}

Keywords:Hydropower; Resources; Hydropower plant(HPP); Generation of electricity; Hydropower potential

\section{Introduction}

Georgia, having rivers with high energy potential, is reach with hydropower. This fact is partially compensating the fuel deficit of the country. Georgia has rich hydropower potential due to the mountainous terrain. Caucasus and small Caucasus mountains have specifically high slope and rivers of those mountains can have high hydropower potential due to ability of gaining high pressure in small distances. The statement is especially true for west Georgia [1]. Totally, there are 26 thousand rivers in Georgia, with total length of 60 thousand $\mathrm{km}$. The rivers with total length of $25 \mathrm{~km}$ and less account for $99.3 \%$ of the total amount of the rivers and for $76 \%$ of the total length of all rivers. Total volume of water flow is $52.8 \mathrm{~km}^{3}$, while the total water resources of Georgia reach $61.5 \mathrm{~km}^{3}$. If we add the amount of fresh water, including the glaciers, lakes, reservoirs, and wetlands, the amount of total water resources will increase up to $96.5 \mathrm{~km}^{3}$ [2].

According to "Hydro Project", 319 out of total amount of rivers have significant hydropower potential, with potential capacity of $15.63 \mathrm{mnkW}$ and average annual generation of $135.8 \mathrm{bl}$. $\mathrm{kWh}$, in total [3]. 208 out of these rivers are small and medium sized rivers with potential capacity of $14.78 \mathrm{GWh}$ and $129.5 \mathrm{TWh}$. The other 111 rivers have potential of 851 thousand $\mathrm{kW}$ ( $7 \%$ of total capacity of the rivers). The energy of total surface waters of Georgia accounts for 228.5TWh, with corresponding capacity of $26.1 \mathrm{GWh}$. According to the studies of the same institute, if we take into account the theoretical amount of hydropower potential of the main rivers in Georgia, we can calculate the amount of river flows per square meter, accounting for $3.27 \mathrm{GWh}$ for the total country; $5.06 \mathrm{GWh}$ for eastern Georgia and 1.73GWh for west Georgia [4]. In terms of absolute numbers, we can see that 228.5TWh (72.1\%) falls on west Georgia and 63.7TWh (27.9\%) - on the eastern Georgia [5].

If we separate the potential of small, medium and large rivers, we can assume that they account for 60\% (135.8TWh) of total energy potential of surface waters, with additional 40\% (92.7blkWh) falling on the waters from the mountains (see Table 1): Theoretical hydro potential of large and medium rivers is $136 \mathrm{TWh}$, which is $3.4 \%$ of the total hydro potential of all rivers on the territory of former soviet republics $[6,7]$. Technical hydro potential of Georgia is $81 \mathrm{blkWh}$; while economic hydro potential equals $39 \mathrm{TWh}$. Hydro potential per each square meter of current territory of Georgia is 1943ths $\mathrm{kWh}$, one of the highest figures worldwide. Georgia was on third place in USSR countries by per capita hydro potential and was above the average USSR data by $41.7 \%$ [8].

Table 1: Hydropower sources.

\begin{tabular}{|c|c|c|c|}
\hline Hydropower Sources & Capacity & Energy & TWh \\
\hline TWh & TWh potential of surface water Flows & 26.08 & 228.5 \\
\hline
\end{tabular}




\begin{tabular}{|c|c|c|c|}
\hline Theoretical potential of large, medium and small rivers (319 rivers) & 15.62 & 135.8 & 59.5 \\
\hline Theoretical potential of water flow from mountains & 10.46 & 92.7 & 40.5 \\
\hline
\end{tabular}

Table 2: Economic potential for main rivers of Georgia.

\begin{tabular}{|c|c|c|}
\hline Name of the River & Annual Economic Potential bl. kWh & Share from Total Economic Potential \% \\
\hline Enguri & 10.7 & 27.4 \\
\hline Rioni with Tskhenistskali & 8.3 & 14.6 \\
\hline Kodi & 5.7 & 9.7 \\
\hline Alazan of Tusheti & 3.8 & 9 \\
\hline Mtkvari with Aragvi & 3.5 & 6.4 \\
\hline Bzifi & 2.5 & 5.1 \\
\hline Khrami and Faravani & 2.0 & 2.1 \\
\hline Shaori and Tkibuli & 0.8 & 4.4 \\
\hline Small rivers & 1.7 & 100.0 \\
\hline All & 39.0 & \\
\hline
\end{tabular}

Additionally, favorable condition for HPP construction is that $40 \%$ of technically possible hydro potential of all 319 rivers is concentrated on eight main rivers (Mtkvari, Rioni, Enguri, Tskhenistskali, Kodori, Bzifi, Khrami and Aragvi). Economic potential for main rivers of Georgia is given in Table 2 [9]. Abovementioned hydro potential of Georgia (135.8TWh) reflects capacity of 319 small and medium rivers. It is well-known, that the seasonal distribution of the potential hydro capacity is theoretically dependent only on the seasonality of the river flaws [10]. Also, the reallocation within the year of within different years is possible by construction of conventional HPPs, this is why the seasonality of water flaw, considering overall energy situation, is the most important for development of country's thermal-electric complex.

Below is given data of annual seasonal distribution of hydropower potential for main rivers of Georgia, given as a percentage from the annual potential (see Table 3): We should hereby note, that the theories revealing, evaluating and calculating potential usage of hydropower is based on the data of the previous century and needs additional evaluation according to modern standards. The works toward this direction are at the very initial stage. Engineering assistance of the hydropower development needs additional funds for the field works and desk study. Annual technically feasible hydro potential of large and medium HPPs is $81 \mathrm{TWh}, 73 \%$ of which is in west Georgia (59TWh) and 27\% in east Georgia (22TWh.)

Table 3: Annual distribution of hydropower potential for main rivers of Georgia.

\begin{tabular}{|c|c|c|c|c|c|}
\hline \multirow{2}{*}{ Territory } & Area & \multicolumn{4}{|c|}{ Seasonal Distribution of Resources. \% } \\
\cline { 3 - 6 } km $^{2}$ ths & Winter & Spring & Summer & Autumn \\
\hline West Georgia & 32.6 & 16.0 & 33.3 & 32.2 & 18.5 \\
\hline East Georgia & 37.3 & 13.8 & 43.6 & 26.6 & 16.0 \\
\hline Total & 69.7 & 15.4 & 36.2 & 30.6 & 17.8 \\
\hline
\end{tabular}

The distribution of the technical potential by the main river basins of the country is given in Table 4 . The economically feasible hydro potential equals about $39 \mathrm{TWh}$, almost $50 \%$ of technically feasible potential. The economically feasible potential of the main river basins of the country is given in Table 4 . Hereby, the hydro potential of the country besides the positive effects has also negative ones: it is unequally distributed on the territory of Georgia. West and east Georgia with almost the same area have $70 \%$ of energy potential falling on west Georgia.

Table 4: Distribution of hydropower potential between the main rivers basins of Georgia.

\begin{tabular}{|c|c|c|c|c|c|c|}
\hline River Basin & $\begin{array}{l}\text { Catchment Area, } \\
\qquad \mathbf{K m}^{2}\end{array}$ & $\begin{array}{c}\text { Average Annual } \\
\text { Capacity, MW }\end{array}$ & Share in & $\begin{array}{l}\text { Average Annual } \\
\text { Generation, Gwh }\end{array}$ & $\begin{array}{l}\text { Per Square Capaci- } \\
\text { ty Ths. kW/km }\end{array}$ & $\begin{array}{l}\text { Per Square Genera- } \\
\text { tion, GWh } / \mathbf{k m}^{2}\end{array}$ \\
\hline Mtkvari & 18243 & 2204 & 14.1 & 19303 & 3.23 & 1.06 \\
\hline Rioni & 13418 & 2985 & 19.1 & 26148 & 3.1 & 1.95 \\
\hline Enguri & 4058 & 2063 & 13.2 & 18071 & 6.82 & 4.45 \\
\hline Kodori & 2036 & 1329 & 8.5 & 11636 & 7.78 & 5.72 \\
\hline Bzifi & 1502 & 797 & 5.1 & 6982 & 5.23 & 4.65 \\
\hline Sum & - & 9378 & 60.0 & 82140 & - & - \\
\hline
\end{tabular}

Table 5 shows the Regional distribution of hydropower potential. Category A includes the rivers on which there are detailed methodological studies, while on category B Rivers there are only approximate calculations. Table 5 shows that all Georgian rivers 
are rich with hydro potential. The most remarkable are: Abkhazia, Svaneti, Imereti, Racha-lechkhumi, Mtkheta-mtianeti, Samegrelo and Shida Qartli. The most remarkable rivers by means of energy potential are: Enguri, Rioni, Mtkvari-where the most of operational HPPs are located and potential once are considered.

Table 5: Regional distribution of hydropower potential.

\begin{tabular}{|c|c|c|c|c|}
\hline Regions & $\begin{array}{c}\text { Number of Category A } \\
\text { Rivers }\end{array}$ & Number of Category A rivers & Total Capacity of the Rivers $10^{3} \mathrm{~kW}$ & Generation GWh. \\
\hline Abkhazia & 40 & 15 & 3644.7 & 31344 \\
\hline Svaneti & 19 & 13 & 3216.0 & 26416 \\
\hline Samegrelo & 11 & 2 & 1736.8 & 15531 \\
\hline Imereti & 23 & 12 & 2577.8 & 20580 \\
\hline Racha-Lechkhumi & 13 & 6 & 2235.4 & 18220 \\
\hline Guria & 7 & - & 508.8 & 4290 \\
\hline Adjara & 14 & 2 & 795.4 & 6490 \\
\hline Samtskhe-Javakheti & 17 & 10 & 667.6 & 5848.2 \\
\hline Kvemo-Qartly & 8 & - & 664.0 & 5784 \\
\hline Shida-Qartly & 20 & 9 & 1670.5 & 14657 \\
\hline Mckheta-Mtianeti & 15 & 18 & 2088.6 & 17925 \\
\hline Kakheti & 29 & 26 & 1527.5 & 11973 \\
\hline
\end{tabular}

Georgia is exceptionally rich with considerably small rivers. Their technically feasible potential is $12.3 \mathrm{TWh}$. In recent years, 300 schemes for deployment of small and medium rivers have been prepared, out of which 229 small HPPs can be located in 47 different districts. Out of them 155 can be located in 28 districts of west Georgia and 73 of them can be located in 19 districts of east Georgia. Total capacity of small HPPs is $2.1 \mathrm{GWh}$; they can generate annual 12.3 TWh. $66.7 \%$ of capacity and $68.38 \%$ of generation falls on west part of Georgia.

Most of Georgian rivers have rough seasonality, which means high water flow in spring-summer period and low water flow in autumn-winter. This is why the effective utilization of the potential can be reached by constructing different types of HPPs, where the impact on natural regimes will be minimal and development of mutual application of natural and artificial systems will take place. For further development of hydro potential, as important energy resource, it is necessary to study and justify the utilization methodologies, definition of locations and parameters of new objects by complex utilization considering the scales and reasonability.

According to Ministry of Energy of Georgia, the international project financed by the grant from Ministry of Foreign affairs of the Kingdom of Netherlands is on-going. The aim of the project is to study the river basins and reveal the list of potential HPPs. The project includes digitalization and justification of existing historic hydrological and meteorological data. As final result we will have the digital map of Georgia in GIS system, where the information on the potential HPPs will appear: coordinates, capacity, generation, amount of investment for construction, etc. Technical-economical parameters of existing and potential HPPs is given in Appendixes.
Table 6: Installed capacity and generation of HPPs in Georgia, 2015.

\begin{tabular}{|c|c|c|c|}
\hline Sr. No & Name of HPP & Generation (GWh) & $\begin{array}{c}\text { Installed Capaci- } \\
\text { ty (MW) }\end{array}$ \\
\hline 1 & Enguri & 3287.41 & 1300 \\
\hline 2 & Vardnili & 557.53 & 220 \\
\hline 3 & Khrami 1 & 225.46 & 1128 \\
\hline 4 & Khrami 2 & 341.77 & 114.4 \\
\hline 5 & Jinvali & 405.81 & 130 \\
\hline 6 & Vartsikhe cascade & 763.19 & 184 \\
\hline 7 & Rioni & 307.07 & 48 \\
\hline 8 & Gumati & 282.33 & 68.8 \\
\hline 9 & Lajanuri & 377.73 & 112.5 \\
\hline 10 & Dzevruli & 117.15 & 80 \\
\hline 11 & Shaori & 106.19 & 38.4 \\
\hline 12 & Zahesi & 185.13 & 36.8 \\
\hline 13 & Ortachala & 78.795 & 18 \\
\hline 14 & Atskhesi & 58.25 & 16 \\
\hline 15 & Chitakhevi & 94.45 & 21 \\
\hline 16 & Satskhene & 18.25 & 14 \\
\hline 17 & Khadori & 135.73 & 24 \\
\hline 18 & Larsi & 67.75 & 19 \\
\hline 19 & Faravani & 407.22 & 86.54 \\
\hline 20 & 48 small HPPs & 508.78 & 160.8 \\
\hline 21 & Total HPPs & 8326.014 & 2804.96 \\
\hline
\end{tabular}

As of January 1, 2016, there are 67 operational HPPs, 19 of which are large and medium sized, and 48 are small sized HPPs 
(see Table 6). 5 HPPs, 4 small and one medium sized have been commissioned in 2016 with total capacity of $116.7 \mathrm{MW}$. Accordingly, in the beginning of 2017 there were 72 operational HPPs with total installed capacity of 2921.66 MW. Most of them are located in west of Georgia (within Enguri and Rioni river basins). Almost half on annual generation is supplied by 7 conventional HPPs, with total installed capacity of 1991MW and annual generation more than 5TWh. Total installed capacity of existing 12 seasonal HPPs is 646MW, while 48 small deregulated (below 13MW) HPPs (total installed capacity of $162 \mathrm{MW}$ ) supply only $5 \%$ of total generation.

The total reservoir volume of conventional HPPs is $2259 \mathrm{mmm}^{3}$ (within it $1425 \mathrm{mnm}^{3}$ is useful volume). Major parts of existing HPPs are old and need modernization in order to increase the efficiency. In most cases, the filling-and-emptying plan is not fulfilled as designed and no energy is accumulated for periods of deficit [11]. We had a boost in HPP construction within over last year's; in particular, 18 HPPs, with total installed capacity of 174MW were commissioned in 2010-2015. With use of modern achievements in hydro construction it is possible to construct dozens of large and medium-sized economically feasible HPPs. Despite this, the utilization level of hydro potential is still low. Hydro generation in 2016 reached 9.2 TWh, only $11.4 \%$ of technical capacity and $23.6 \%$ of economic capacity.

The main challenges for the study of hydro potential and its application are following:

1. Recalculation of hydro potential.

2. Construction of conventional HPPs with seasonal regulation, increasing the winter generation.

3. Construction of conventional HPP complexes, as possible.
4. Construction of hydro hubs, which will create possibility for water flow to be regulated and utilized for irrigation, water supply and electricity.

5. Creation of the list of actions to be conducted for safety and recovery of black sea coast, from the damages caused due to decrease of sediments from the rivers.

Full utilization of the economically feasible local hydro potential.

\section{References}

1. Chomakhidze D, Kublashvili G (2017) Renewable Energy Resources of Georgia, Publishing house Dani Tbilisi in Georgian, Georgia.

2. Jordania Ir, Urushadze T, Faresishvili O, Mirianashvili N, Chomakhidze D, et al. (2015) Natural resources of Georgia, Tbilisi in Georgian, Georgia, pp: 1183.

3. Chomakhidze D, Shengelia G (2017) Energy Complex of Georgia. Lambert Academic Publishing, Germany.

4. Ministry of Energy of Georgia. Georgia's Energy Strategy, Georgia, pp: 2016-2025.

5. Chomakhidze Demur (2006) Energy Balance of Georgia. Georgian Technical University, Tbilisi, Georgia, pp: 353.

6. National Statistics Office of Georgia (GEOSTAT) (2016) Energy Balance of Georgia, Statistical Publication in Georgian.

7. Chomakhidze Demur (2003) Georgian Energy Security, PDP, Tbilisi, Georgia, pp: 545.

8. Mirskhulava D, Chomakhidze D, Arveladze R, Eristavi E, Tsintsadze P, et al. (2004) Energy Strategy of Georgia, Bakur Sulakauri, Tbilisi, Georgia, pp: 297.

9. Georgian National Energy and Water Supply Regulatory Commission, Annual Reports 2000-2015.

10. Georgian Energy Market Operator (ESCO), Annual Reports 2005-2015.

11. (2014) Key World Energy Statistics. pp: 2014.
Creative Commons Attribution 4.0 International License

For possible submissions Click Here

\section{Submit Article}

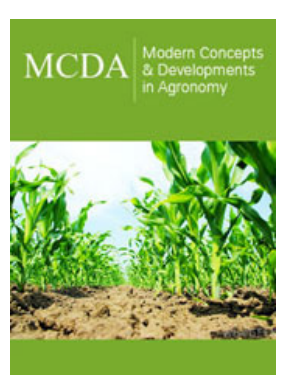

Modern Concepts \& Developments in Agronomy

\section{Benefits of Publishing with us}

- High-level peer review and editorial services

- Freely accessible online immediately upon publication

- Authors retain the copyright to their work

- Licensing it under a Creative Commons license

- Visibility through different online platforms 